\title{
Hypoxia-inducible factor 1 alpha is regulated by RBM38, a RNA- binding protein and a p53 family target, via mRNA translation
}

\author{
Seong-Jun Cho', ${ }^{1}$, I-Fang Teng ${ }^{1,}{ }^{*}$, Min Zhang ${ }^{1}$, Tiffany Yin' ${ }^{1}$, Yong-Sam Jung ${ }^{1}$, Jin \\ Zhang ${ }^{1}$ and Xinbin Chen ${ }^{1}$ \\ ${ }^{1}$ Comparative Oncology Laboratory, Schools of Medicine and Veterinary Medicine, University of California, Davis, CA \\ * These authors contributed equally to this work \\ Correspondence to: Xinbin Chen, email: xbchen@ucdavis.edu
}

Keywords: p53, RBM38, RNPC1, HIFla, mRNA translation

Received: September 10,2014 Accepted: November 15, $2014 \quad$ Published: November 16, 2014

This is an open-access article distributed under the terms of the Creative Commons Attribution License, which permits unrestricted use, distribution, and reproduction in any medium, provided the original author and source are credited.

\section{ABSTRACT}

Hypoxia-inducible factor 1 (HIF1), a heterodimeric transcription factor, consists of HIF1a and HIF1 $\beta$ and is necessary for cell growth and survival under a hypoxic condition. Thus, the level and activity of HIF1a needs to be tightly controlled. Indeed, HIF1a protein stability is controlled by prolyl hydroxylase and von Hippel-Lindaumediated proteosomal degradation. However, it remains unclear whether HIF1a expression is controlled by other pathways. Here, we showed that RNA-binding protein RBM38, a target of the p53 family, regulates HIF1a expression via mRNA translation. Specifically, we showed that under a hypoxic condition, ectopic expression of RBM38 decreased, whereas knockdown of RBM38 increased, the level of HIF1a protein. We also showed that the rate of de novo HIF1a protein synthesis was increased by knockdown of RBM38. Additionally, we showed that RBM38 directly bound to HIF1a 5' and 3'UTRs. Consistently, we showed that the rate of mRNA translation for a heterologous reporter that carries HIF1a 5'and/or 3'UTRs was increased upon knockdown of RBM38. Furthermore, we showed that knockdown of RBM38 increased, whereas ectopic expression of RBM38 decreased, the binding of eIF4E to HIF1a mRNA. Together, our data suggest that RBM38 is a novel translational regulator of HIF1a under a hypoxic condition.

\section{INTRODUCTION}

Hypoxia (low oxygen tension) induces an array of cellular processes to maintain ATP production via glycolysis and other survival pathways [1, 2]. Hypoxiainducible factor 1 (HIF1), a well-defined hypoxia responsive factor, consists of two distinct subunits, HIF 1 alpha (HIF $1 \alpha$ ) and HIF1 $\beta$ (ARNT). HIF1 belongs to a subfamily of the basic-helix-loop-helix-PAS transcription factors [3]. In response to high levels of oxygen, HIF1 $\alpha$ protein is modified by prolyl hydroxylase and rapidly degraded through the VHL-mediated proteasomal pathway [1]. Once normoxia turns into hypoxia, prolyl hydroxylase is inactivated and subsequently, HIF $1 \alpha$ is rapidly stabilized through decreased degradation [3]. Upon accumulation, HIF $1 \alpha$ induces an array of target genes associated with cell survival (insulin-like growth factor-binding protein-1, Nip3), angiogenesis (vascular endothelial growth factor
A, angiopoietin-2, plasminogen activator inhibitor-1), and energy metabolism (glucose transporter-1, hexokinase-2, glyceraladehyde-3-phosphate dehydrogenase) [1, 3]. Additionally, HIF $1 \alpha$ appears to possess transcriptionindependent activities through physical interaction with c-Myc and Cdc6 to regulate the cell cycle [4-6].

RBM38, also called RNPC1, is a target of the p53 family and a RNA recognition motif (RRM)-containing RNA binding protein [7]. RBM38 is expressed primarily as RBM38 (239 amino acids) along with a minor isoform, RBM38b (121 amino acids). RBM38b has a sequence identical to the N-terminal region of RBM38. RBM38 is known to regulate mRNA translation of p53 and mRNA stability of p21, HuR, p63, p73, MDM2, and MIC-1 transcripts [7-13].

Although HIF $1 \alpha$ expression is mainly regulated by post-translational modifications and protein stability [3, 14], other pathways have been found to regulate HIF $1 \alpha$ 
expression, including transcription and translation [15]. In this study, we showed that ectopic expression of RBM38 decreased, whereas knockdown of RBM38 increased, the level of HIF1 $\alpha$ protein under a hypoxic condition. Moreover, we found that knockdown of RBM38 enhanced HIF $1 \alpha$ mRNA translation via binding to HIF $1 \alpha 5^{\prime}$ and 3'UTRs. Together, we uncovered a novel mechanism by which HIF $1 \alpha$ is regulated by the p53 pathway via RBM38.

\section{RESULTS}

\section{HIF1 $\alpha$ expression is regulated by RBM38 under a hypoxic condition}

HIF $1 \alpha$ is necessary for cell survival under a hypoxic condition and its expression is controlled by multiple positive and negative regulators in addition to VHLmediated proteasomal degradation [16]. Since HIF1 $\alpha$ has

A

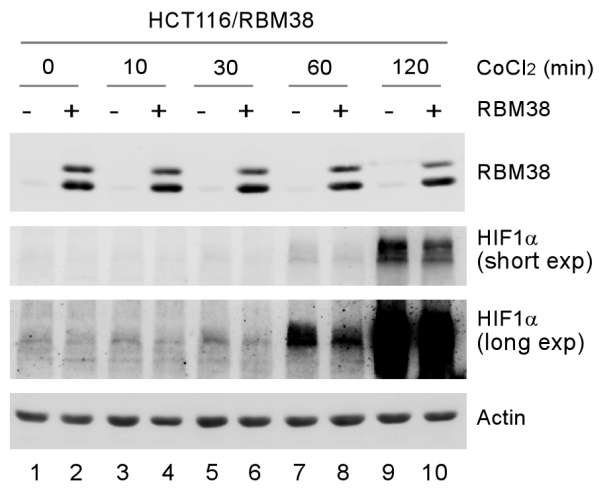

B

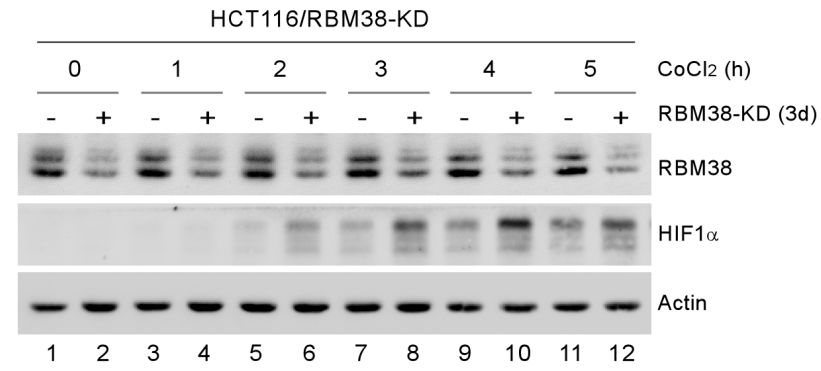

C

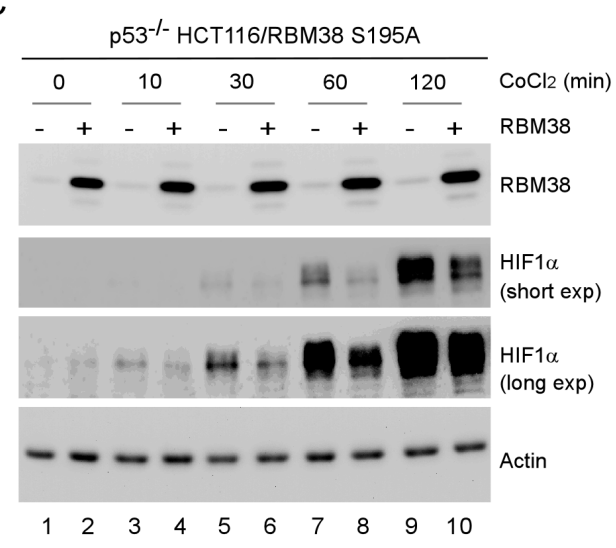

D

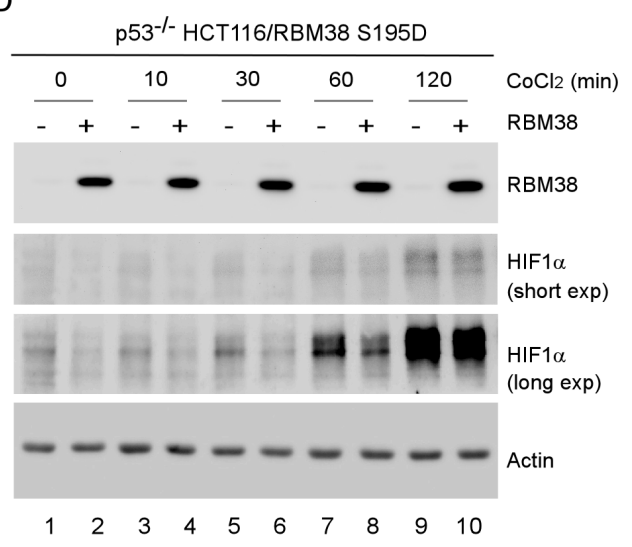

Figure 1: HIF1 $\alpha$ expression is regulated by RBM38 under a hypoxic condition. (A) HCT116 cells were uninduced (-) or induced $(+)$ to express RBM38 with doxycycline for $24 \mathrm{~h}$ and then treated with $500 \mu \mathrm{M} \mathrm{CoCl}$ for the indicated times. The levels of RBM38, HIF $1 \alpha$, and actin were measured by Western blotting. (B) HCT116 cells were uninduced (-) or induced (+) to knock down RBM38 with doxycycline for 3 days and then treated with $500 \mu \mathrm{M} \mathrm{CoCl}_{2}$ for the indicated times. The levels of RBM38, HIF1 $\alpha$, and actin were measured by Western blotting. (C-D) p53/- HCT116 cells were uninduced (-) or induced (+) to express RBM38-S195A (C) or RBM38$\mathrm{S} 195 \mathrm{D}$ for $48 \mathrm{~h}$ and then treated with $500 \mu \mathrm{M} \mathrm{CoCl}_{2}$ for the indicated times. The experiments were performed as in (A). 
a long 3'UTR along with an AU-rich element (ARE), we examined whether HIF1 $\alpha$ expression is modulated by RNA-binding protein RBM38, a target of the p53 family and a potent regulator of multiple pro-survival and prodeath factors [7-13]. To test this, HCT116 cell line in which RBM38 can be inducibly expressed under the control of a tetracycline-regulated promoter was used. We showed that the level of HIF1 $\alpha$ protein was decreased by RBM38 in HCT116 cells treated with $\mathrm{CoCl}_{2}$, a hypoxia mimetic (Fig. 1A). Next, we examined whether knockdown of RBM38 has an opposite effect on HIF $1 \alpha$ expression under a hypoxic condition. To test this, HCT116 cell line in which RBM38 can be inducibly knocked down under the control of a tetracycline-regulated promoter was used. We found that under a hypoxia-mimic condition $\left(\mathrm{CoCl}_{2}\right.$ treatment), the levels of HIF1 $\alpha$ protein were increased by knockdown of RBM38 in a time-dependent manner (Fig. 1B).

Previously, we showed that phosphorylation of RBM38 modulates RBM38 to regulate p53 expression. To test this, the effect of phosphorylation of RBM38 on HIF1a expression was measured in p53-null HCT116 cells, which can inducibly express RBM38-S195A, a non-phosphorylatable form, or RBM38-S195D, a phosphor-mimetic. We found that under a hypoxia-mimic condition $\left(\mathrm{CoCl}_{2}\right.$ treatment), the levels of $\mathrm{HIF} 1 \alpha$ protein were decreased by both RBM38-S195A and RBM38S195D (Fig. 1C-D), suggesting that RBM38 is capable of regulating HIF1 $\alpha$ regardless of its phosphorylation status.

To confirm the regulation of HIF $1 \alpha$ by RBM38 under a hypoxic condition, MCF7 and HCT116 cells were transduced with a lentivirus expressing RBM38 shRNA or luciferase shRNA for $3 \mathrm{~d}$ and then incubated under a hypoxia condition $(\sim 0.1 \%$ oxygen) for various times. As a control, the levels of p53 protein were measured and found to be increased by knockdown of RBM38 regardless of the condition of oxygen tension (Fig. 2A-B, p53 panels), consistent with our previous studies [9, 17]. Interestingly, we found that the levels of HIF $1 \alpha$ in both MCF7 and HCT116 cells were increased upon knockdown of RBM38 under a hypoxic condition for $6 \mathrm{~h}$, but little if any under the same condition for $3 \mathrm{~h}$ (Fig. 2A-B, compare lanes 3 and 5 with lanes 4 and 6, respectively). Since p53 is capable of destabilizing HIF $1 \alpha$ protein through the ubiquitin-dependent proteasomal degradation pathway $[9$,
A

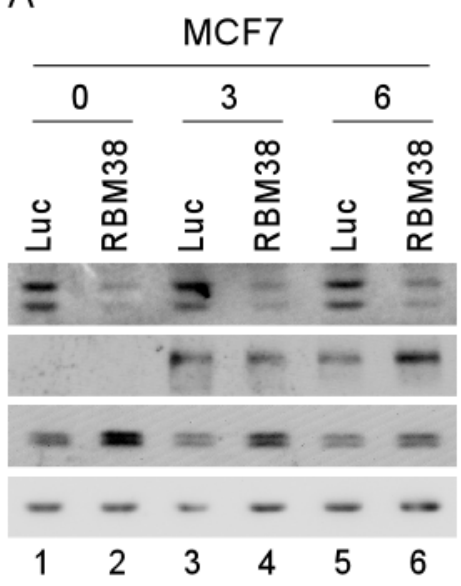

C

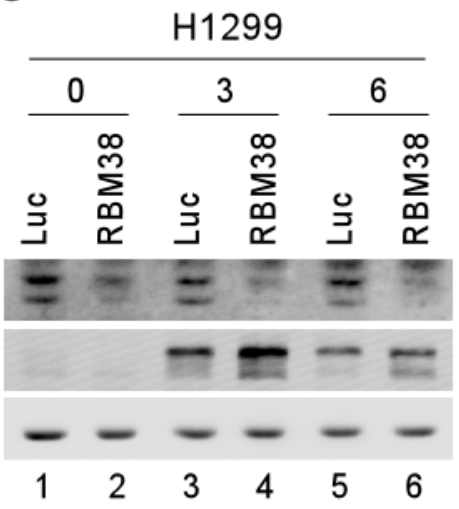

B

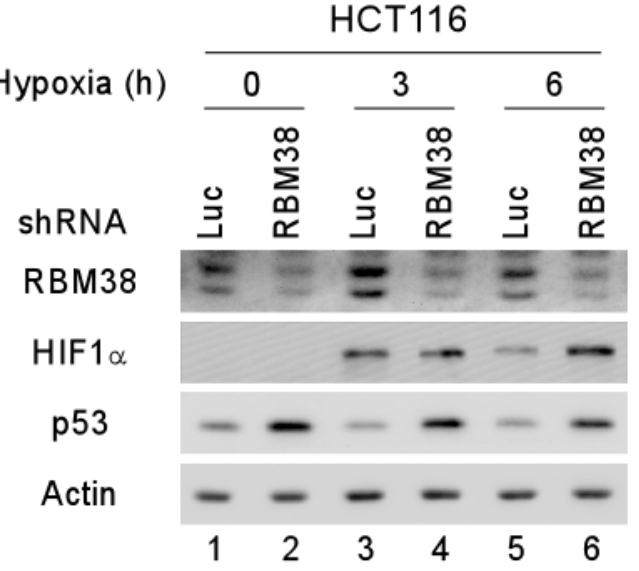

D

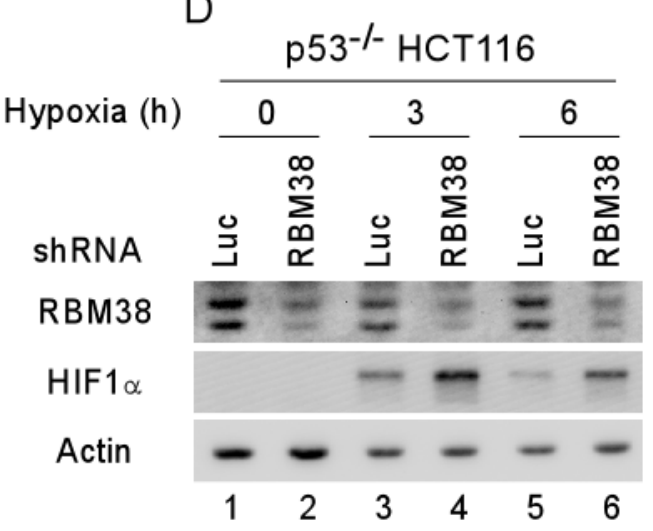

Figure 2: HIF1 $\alpha$ expression is increased by knockdown of RBM38 under a hypoxic condition. MCF7 (A), HCT116 (B), H1299 (C), and p53 ${ }^{-/}$HCT116 (D) cells were transduced with a lentivirus expressing a control luciferase (Luc) shRNA or RBM38 shRNA, selected by puromycin for $3 \mathrm{~d}$, and then exposed to hypoxia for 0,3 , or $6 \mathrm{~h}$. Whole cell lysates were collected and the levels of RBM38, HIF1 $\alpha$, p53, or actin were determined by Western blot analysis. 
14], p53-null HCT116 and H1299 cells were used to rule out potential effects of wild-type p53 on RBM38-mediated HIF $1 \alpha$ regulation. Indeed, we found that the levels of HIF $1 \alpha$ protein were markedly increased by knockdown of RBM38 under the same hypoxic condition for both 3 and $6 \mathrm{~h}$ (Fig. 2C-D, compare lanes 3 and 5 with 4 and 6 , respectively). Together, these data suggest that RBM38 is necessary for maintaining proper expression of HIF $1 \alpha$ under a hypoxic condition.

\section{RBM38 regulates HIF1 $\alpha$ mRNA translation}

As an RNA-binding protein, RBM38 is known to regulate gene expression through post-transcriptional mechanisms, including mRNA stability and translation [9]. To explore how RBM38 regulates HIF $1 \alpha$ expression under a hypoxic condition, RT-PCR was performed to measure the level of HIF $1 \alpha$ transcript in H1299 and p53/- HCT116 cells upon knockdown of RBM38. We showed that the levels of RBM38 transcript were decreased by shRNA against RBM38 in $\mathrm{H} 1299$ and p53 ${ }^{-/}$HCT116 cells exposed to hypoxia for various times (Fig. 3A-B). However, the levels of HIF $1 \alpha$ transcript were not significantly altered by knockdown of RBM38 under both normoxic and hypoxic conditions (Fig. 3A-B). Similarly, under a hypoxiamimic condition, the levels of HIF $1 \alpha$ transcript were not significantly altered by knockdown of RBM38 in H1299 cells (Fig. 3C). Thus, we postulate that RBM38 regulates HIF $1 \alpha$ expression potentially through mRNA translation. To test this, we measured the levels of newly synthesized HIF $1 \alpha$ protein in ${ }^{35} \mathrm{~S}$-labeled H1299 and p53/- HCT116 cells treated with $\mathrm{CoCl}_{2}$ for $3 \mathrm{~h}$. Indeed, we found that the levels of newly synthesized HIF $1 \alpha$ protein were markedly increased (2.37 and 2.86 fold) by knockdown of RBM38 in H1299 and p53/- HCT116 cells (Fig. 4A-B). Together, these data suggest that RBM38 regulates HIF $1 \alpha$ mRNA translation under a hypoxic condition.
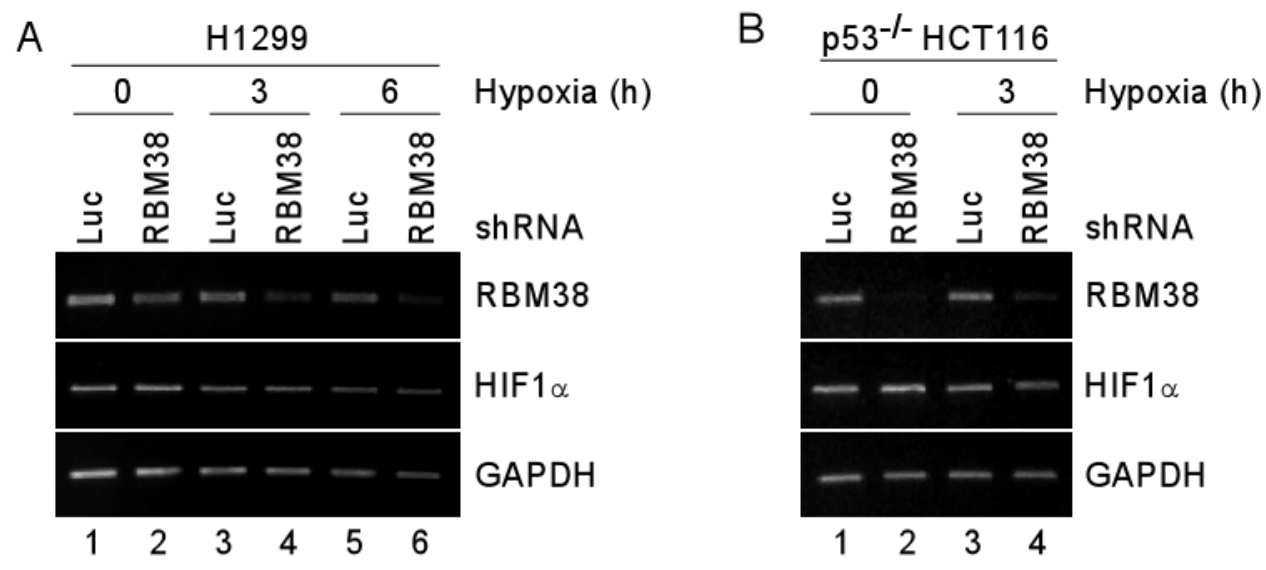

C
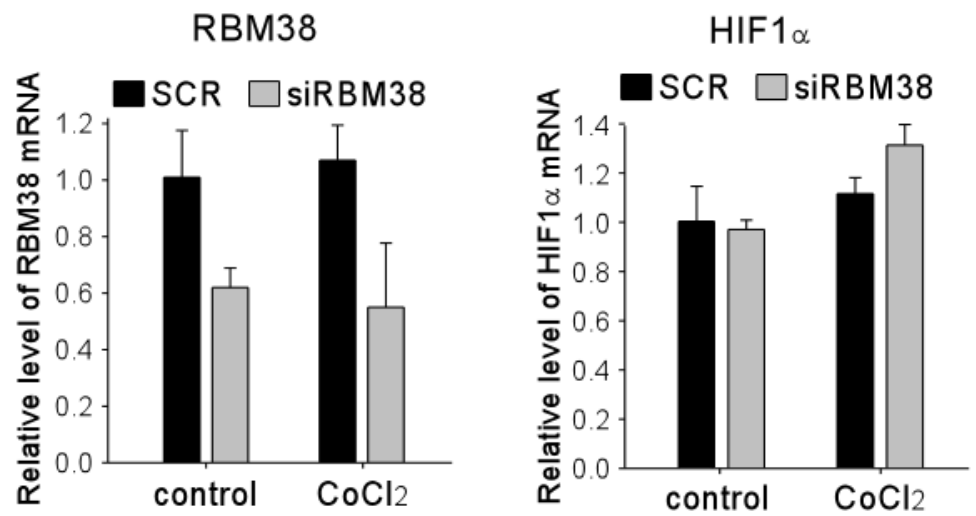

Figure 3: Knockdown of RBM38 has no effect on the level of HIF1 $\alpha$ mRNA. (A-B) H1299 (A) and p53 $3^{-/}$HCT116 (B) cells were transduced with a lentivirus expressing a control luciferase (Luc) shRNA or RBM38 shRNA for 3 d, followed by exposure to hypoxia for 0-6 h for H1299 (A), and 0-3 h for p53 ${ }^{-/-}$HCT116 (B) cells. Total RNAs were isolated and RT-PCR was performed to measure the levels of RBM38, HIF1 $\alpha$, and GAPDH transcripts. (C) H1299 cells were transiently transfected with scramble siRNA (SCR) or siRNA against Rbm38 (SiRBM38) for $48 \mathrm{~h}$, followed by treatment with $500 \mu \mathrm{M} \mathrm{CoCl}_{2}$ for $3 \mathrm{~h}$. Total RNAs were isolated and quantitative RT-PCR was performed in triplicates to measure the levels of RBM38, HIF1 $\alpha$, and GAPDH transcripts. The levels of RBM38 and HIF1 $\alpha$ transcripts were normalized to that of the GAPDH transcript. The relative fold change for RBM38 (left panel) and for HIF $1 \alpha$ (right panel) is the ratio of the transcript level in cells with knockdown of RBM38 versus that in cells transfected with a control scrambled siRNA. 


\section{RBM38 directly binds to HIF1 $\alpha$ transcript}

Considering that RBM38 is an RNA-binding protein, we postulate that the binding of RBM38 to HIF $1 \alpha$ mRNA is required for regulating HIF $1 \alpha$ expression. To test this, RNA immunoprecipitation was performed and showed that HIF $1 \alpha$ mRNA was highly enriched in antiRBM38-immunocomplexes, (Fig. 5A, HIF1 $\alpha$ panel, compare lane 2 with 3 ). In addition, RBM38 was found to interact with p21 transcript (Fig. 5A, p21 panel), consistent with previous reports $[7,18]$. In contrast, no interaction was found between GAPDH transcript and RBM38 (Fig. $5 A)$. Next, a set of HIF $1 \alpha$ RNA probes were generated and used for RNA Electrophoretic Mobility Shift Assay (REMSA) to map the binding sites of RBM38 in HIF1 $\alpha$ transcript (Fig. 5B). We showed that recombinant RBM38 protein bound strongly to HIF $1 \alpha 5^{\prime}$ UTR (Fig. 5C) and 3'UTR (Fig. 5E, compare lanes 3-4). The binding of RBM38 to a probe derived from p21 3'UTR, which is known to carry a RBM38-response element [18], was performed and used as a positive control (Fig. 5E, compare lanes 1-2). To confirm the specificity of RBM38 binding to HIF $1 \alpha$ transcript, RNA competition assay was performed and showed that the binding of RBM38 to HIF $1 \alpha$ 5'UTR was abrogated by an excess amount of cold HIF $1 \alpha 5^{\prime} \mathrm{UTR}$ or $\mathrm{p} 21$ probe (Fig. 5D, compare lanes
2 with 3-4, respectively). Similarly, the binding of RBM38 to HIF $1 \alpha$ 3'UTR was abrogated by an excess amount of cold HIF $1 \alpha$ 3'UTR (Fig. 5E, compare lanes 4-5) or cold p21 probe (Fig. 5F, compare lanes 2-3). To define the RBM38-binding site in HIF $1 \alpha$ 3'UTR, three additional RNA probes, fragments A-C, were generated (Fig. 5B). We showed that RBM38 bound strongly to probe $\mathrm{B}$, but not to A and C (Fig. 5G). Additionally, the binding of RBM38 to HIF $1 \alpha$ 3'UTR probe was markedly inhibited by an excess amount of cold probe B and $3^{\prime} \mathrm{UTR}$, but not by probe A (Fig. 5H, compare lanes 2 with 3-5, respectively). To further map the RBM38-binding site in fragment $\mathrm{B}$, two sub-fragments, B1 and B2, were generated (Fig. 5B). We showed that RBM38 bound strongly to probes $\mathrm{B}$ and B1, but only weakly to B2 (Fig. 5I, compare lanes 1, 3, and 5 with 2, 4, and 6 , respectively). These data suggest that RBM38 can directly bind to both HIF $1 \alpha 5^{\prime}$ and $3^{\prime}$ UTRs.

\section{RBM38 regulates HIF1a mRNA translation through HIF1a 5' and 3' UTRs}

To determine whether HIF $1 \alpha 5^{\prime}$ and/or 3'UTRs are necessary and sufficient for RBM38 to regulate HIF $1 \alpha$ mRNA translation, we generated five reporter vectors (Fig. $6 \mathrm{~A})$ : EGFP reporter coding region alone; EGFP along with
A

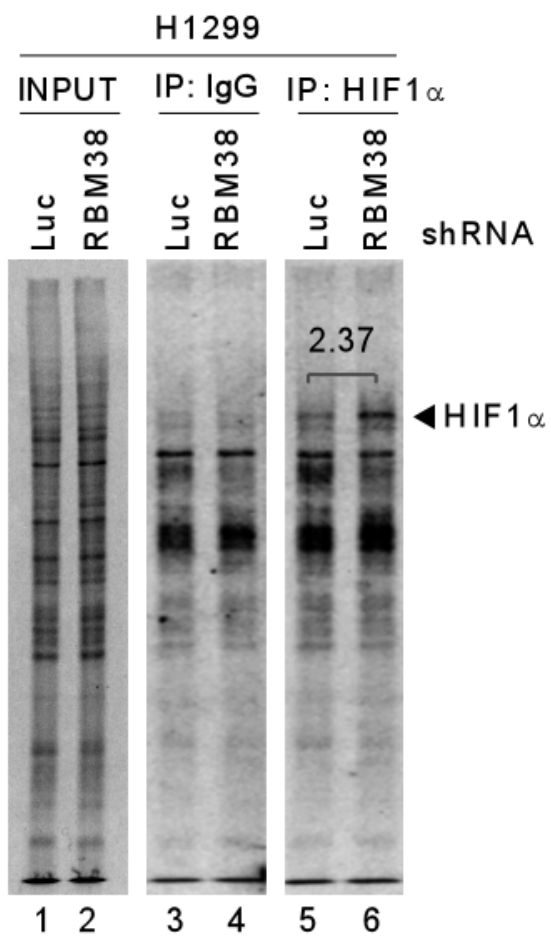

B

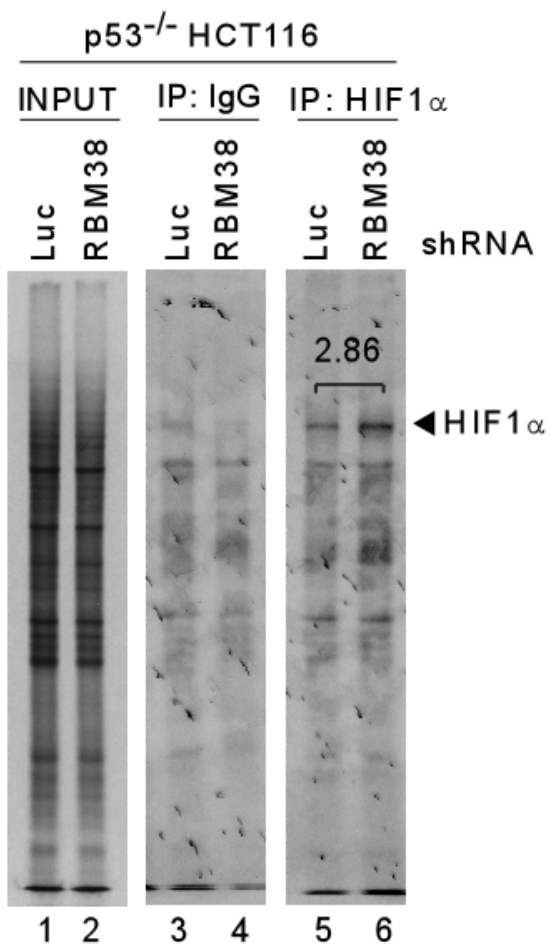

Figure 4: Knockdown of RBM38 enhances HIF1 $\alpha$ expression through mRNA translation. ${ }^{35}$ S-metabolic labeling assay was performed with H1299 (A) or p53 $3^{-\leftarrow}$ HCT116 (B) cells. Cells were transduced with a lentivirus expressing a control luciferase (Luc) shRNA or RBM38 shRNA, selected by puromycin for $3 \mathrm{~d}$, and then treated with $500 \mu \mathrm{M} \mathrm{CoCl}_{2}$ for $3 \mathrm{~h}$, followed by labeling with ${ }^{35} \mathrm{~S}$-methionine and ${ }^{35}$ S-leucine. Cell lysates were isolated and used for immunoprecipitation with anti-HIF $1 \alpha$ (H1 $\alpha 67$, Sigma) or non-immune mouse IgG. The samples from immunoprecipitation were separated in $8 \%$ SDS/PAGE and the protein signals were captured by autoradiography. 
A

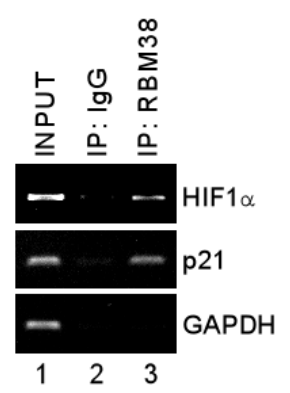

B

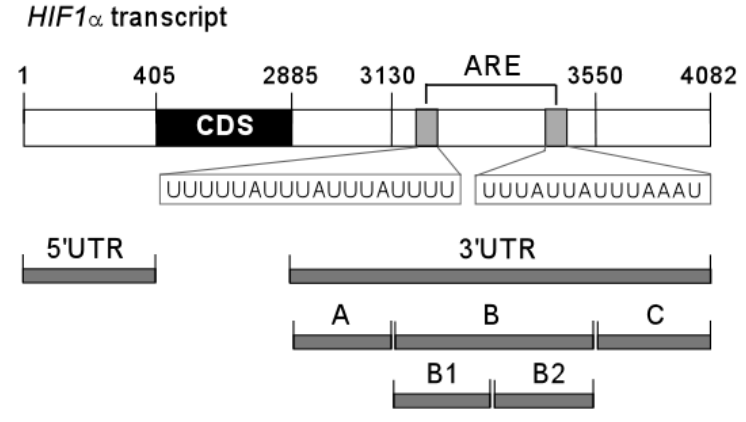

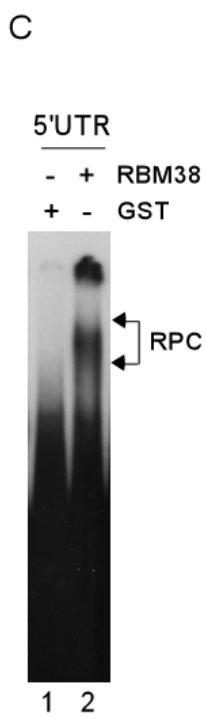

G

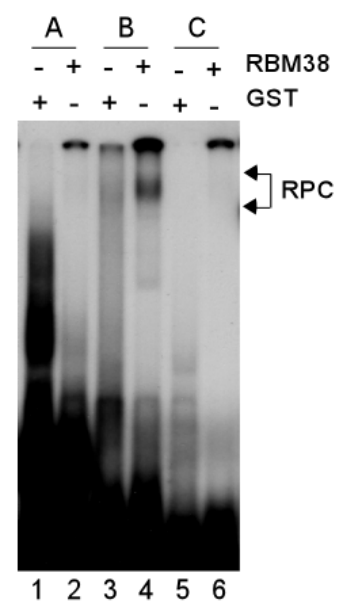

D

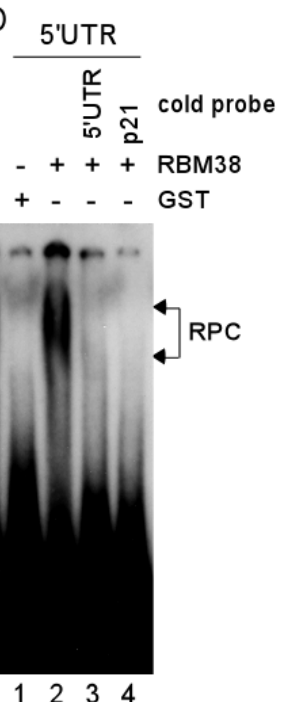

E

$\frac{\mathrm{p} 21}{-\ldots} \frac{3 \text { UTR }}{\ldots+}$ cold probe

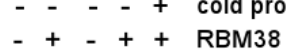

++- GST

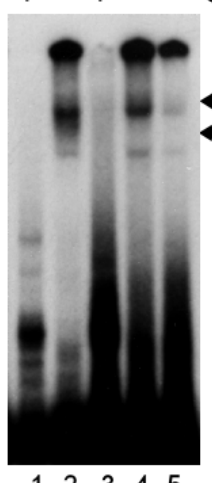

$\mathrm{F}$

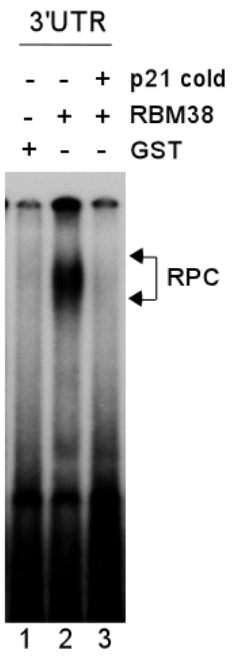

$\mathrm{H} \stackrel{\underline{r}}{\frac{x}{5}}$

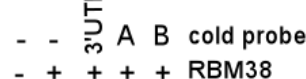

+ - $-\quad$ GST

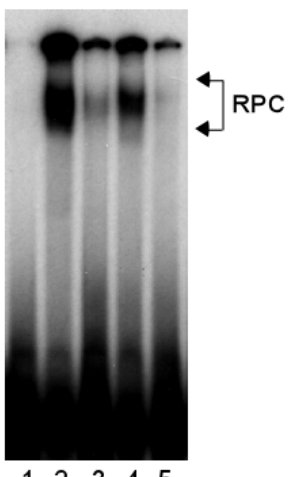

I

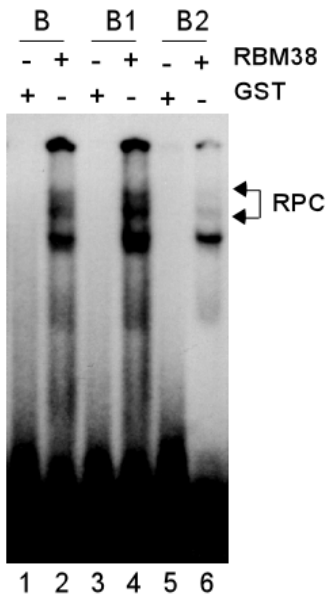

Figure 5: RBM38 directly binds to HIF1 $\alpha$ 5' $^{\prime}$ and 3' UTRs. (A) Whole cell lysates from H1299 cells were collected and immunoprecipitated with anti-RBM38 antibody or control IgG, followed by RT-PCR to determine the level of HIF1 $\alpha$ transcripts in control IgG and anti-RBM38 immunocomplexes. The levels of p21 and GAPDH transcripts were measured as positive and negative controls, respectively. (B) Schematic presentation of HIF1 1 transcript and the location of probes. Putative ARE regions are shown in shaded box. (C) REMSA was performed by mixing ${ }^{32} \mathrm{P}$-labeled RNA probe, HIF $1 \alpha 5^{\prime} \mathrm{UTR}$, with recombinant GST or GST-fused RBM38. (D) REMSA assay was performed by mixing ${ }^{32} \mathrm{P}$-labeled RNA probe, HIF $1 \alpha 5^{\prime} \mathrm{UTR}$, along with or without an excess amount (50-fold) of unlabeled HIF $1 \alpha$ 5'UTR or p21 probe. (E-F) REMSA was performed by mixing ${ }^{32}$ P-labeled RNA probe (p21 or HIF $1 \alpha{ }^{3}$ 'UTR probe) with recombinant GST or GST-fused RBM38 along with or without an excess amount (50-fold) of unlabeled HIF $1 \alpha 3^{\prime} \mathrm{UTR}$ (E) or p21 probe (F). (G) REMSA was performed by mixing ${ }^{32}$ P-labeled RNA probe (fragment A, B, or C) with recombinant GST or GST-fused RBM38. (H) REMSA was performed as described in (F) except that cold HIF $1 \alpha 3^{\prime} \mathrm{UTR}$, fragment A, or fragment B was used. (I) REMSA was performed as described in $(\mathrm{G})$ except that probes B, B1, and B2 were used. The arrow indicates RNA-protein complexes. 
A

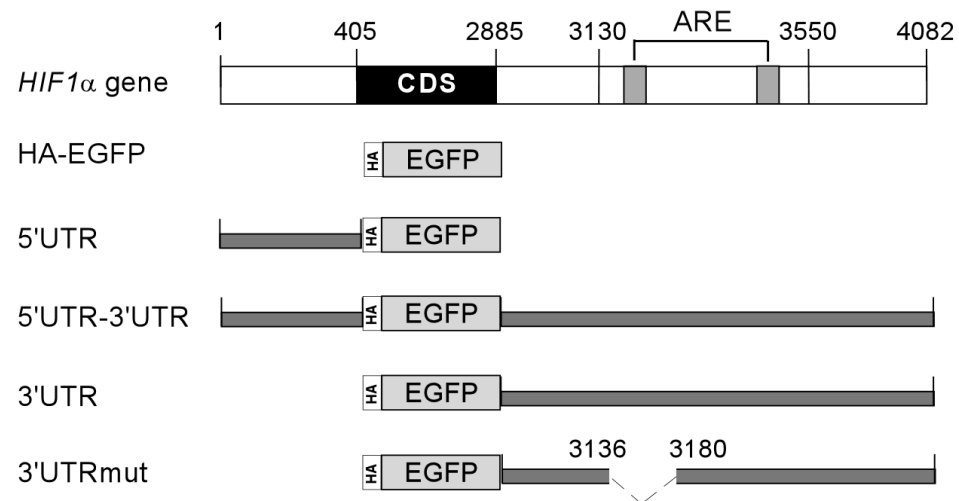

auuuuaaaaaaugcaccuuuuuauuuauuuauuuuuggcuaggga

B

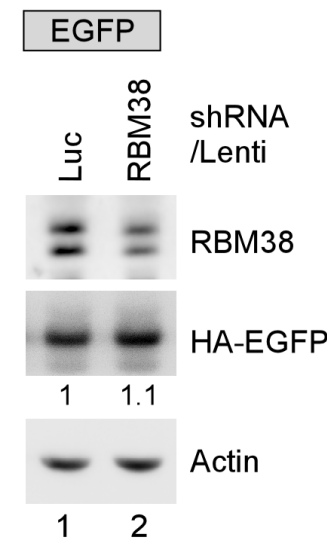

C

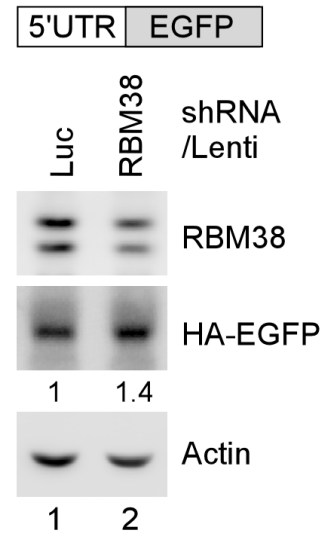

D

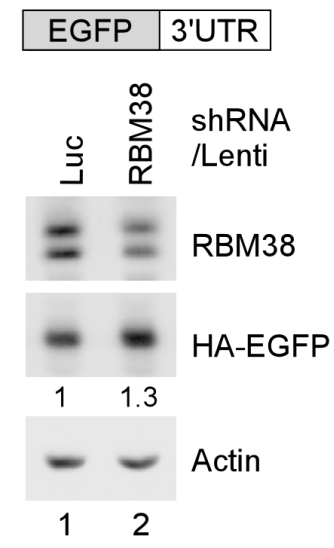

$\mathrm{E}$ \begin{tabular}{|l|l|l|}
\hline 5'UTR & EGFP & 3'UTR \\
\hline
\end{tabular}

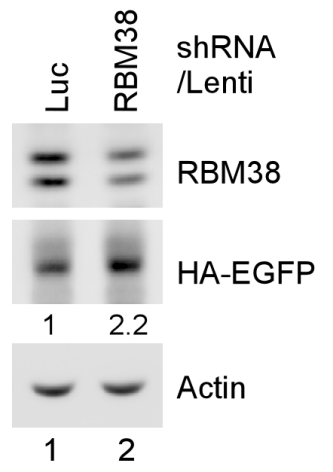

$\mathrm{F}$

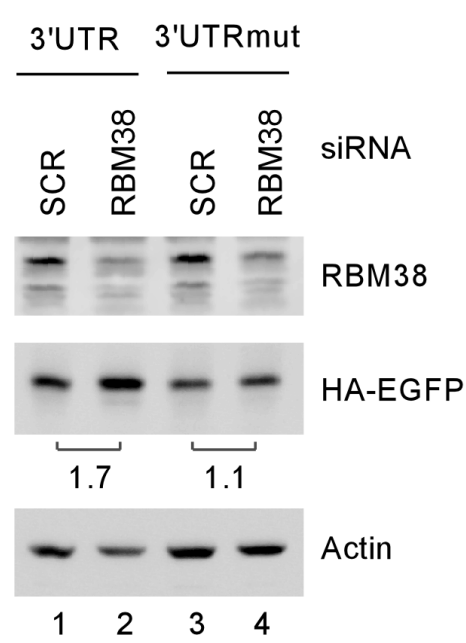

G
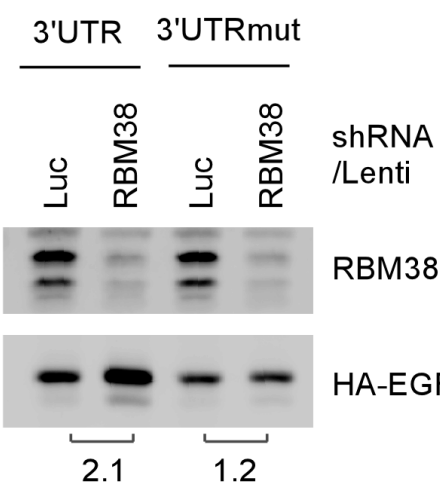

HA-EGFP

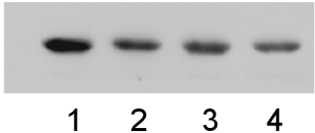

Actin

Figure 6: HIF1 $\alpha 5^{\prime}$ and 3'UTRs are necessary and sufficient for RBM38 to regulate HIF1 $\alpha$ expression. (A) Schematic diagram of the HIF1 $\alpha$ transcript and EGFP reporters along with HIF1a 5' and/or 3' UTRs. Deletion mutation in ARE region of HIF1 $\alpha$ $3^{\prime} \mathrm{UTR}$ is shown in dash line. (B-E) p53--HCT116 cells were transduced with a lentivirus expressing control luciferase shRNA or RBM38 shRNAfor $48 \mathrm{~h}$, and then transiently transfected with an EGFP expression vector that contains the coding region alone (B) or in combination with HIF1 $\alpha 5^{\prime}$ UTR (C), $3^{\prime}$ UTR (D), or both (E). (F) p53־HCT116 cells were transfected with scramble siRNA (SCR) or siRNA against RBM38 for 3 days, and then transiently transfected with an EGFP expression vector that contains HIF $1 \alpha$ 3'UTR or HIF $1 \alpha$ 3'UTRmut. (G) p53-HCT116 cells were transduced with a lentivirus expressing control luciferase shRNA or RBM38 shRNA, selected by puromycin for 3 days and then transiently transfected with an EGFP expression vector that contains HIF1 $\alpha$ 3'UTR or HIF1 $\alpha$ 3'UTRmut. Whole cell lysates were collected and the levels of RBM38, HA-EGFP, and actin were determined by Western blot analysis. 
HIF1 $\alpha$ 5' UTR; EGFP along with HIF $1 \alpha$ 3' UTR; EGFP along with HIF1 $\alpha 5^{\prime}$ and 3' UTRs; and EGFP along with mutant HIF1 $\alpha$ 3' UTR, which lacks the RBM38-binding site in the B1 segment as showed in Fig. 5I. We showed that in p53/- HCT116 cells, knockdown of RBM38 had no effect on EGFP expression for a vector that does not carry any sequence from HIF $1 \alpha$ transcript (Fig. 6B). Interestingly, the levels of EGFP protein were increased by 1.4 -fold for the vector that carries HIF $1 \alpha 5^{\prime}$ UTR (Fig. 6C), 1.3-fold for the vector that carries HIF1 $\alpha 3^{\prime}$ UTR (Fig. $6 \mathrm{D})$, and 2.2-fold for the vector that carries both HIF $1 \alpha 5$, and 3' UTRs (Fig. 6E). Most importantly, we showed that the level of EGFP protein was not significantly increased by knockdown of RBM38 for the vector that carries mutant HIF1 $\alpha$ 3'UTR (3'UTRmut) (Fig. 6F-G, compare lanes 3-4). Again, as a control, knockdown of RBM38 by siRNA and shRNA led to increased expression of EGFP for the vector carries HIF1 $\alpha$ 3'UTR (Fig. 6F-G, compare lanes 1-2).

\section{RBM38 modulates the binding of eIF4E to the cap structure on HIF1 $\alpha$ mRNA}

To explore the mechanism by which RBM38 regulates HIF1 $\alpha$ mRNA translation, we examined whether RBM38 modulates the binding of eIF4E, a key component of translation initiation complex eIF4F, to the cap structure of HIF1a mRNA in p53/- HCT116 cells. RNA immunoprecipitation followed by RT-PCR assay was performed and showed that the level of eIF4E associated with HIF $1 \alpha$ mRNA was increased (2.86-fold) upon knockdown of RBM38 in p53 ${ }^{-/}$HCT116 cells at a low oxygen condition (Fig. 7A). In contrast, the level of eIF4E associated with HIF1 $\alpha$ mRNA was decreased (0.68fold) upon ectopic expression of RBM38 in $\mathrm{p} 53^{-/-} \mathrm{HCT}$
116 cells treated with $500 \mu \mathrm{M} \mathrm{CoCl}_{2}$ for 2 hours (Fig. 7B). These results suggest that RBM38 prevents eIF4E from binding to HIF $1 \alpha$ transcripts, and thus inhibits HIF $1 \alpha$ mRNA translation.

\section{DISCUSSION}

HIF $1 \alpha$ plays a critical role in hypoxia to improve glycolysis, oxygen delivery, and angiogenesis for tumor cells $[1,3]$. Although HIF $1 \alpha$ is mainly regulated by VHLmediated proteasomal degradation, it can be regulated by other post-transcriptional mechanisms [16]. Indeed, we found a novel mechanism by which HIF $1 \alpha$ expression is regulated by $\mathrm{RBM} 38$ via mRNA translation. We also found that RBM38 directly binds to HIF $1 \alpha 5^{\prime}$ and 3'UTRs. Additionally, an ARE element in HIF1 $\alpha$ 3'UTR is recognized by RBM38. Importantly, we showed that both HIF $1 \alpha$ 5'and 3' UTRs are necessary and sufficient for RBM38 to regulate HIF $1 \alpha$ mRNA translation. Since RBM38 inhibits the binding of eIF4E to HIF1 $\alpha$ cap structure, we postulate that upon binding to HIF $1 \alpha 5$, and/or 3' UTRs, RBM38 may physically hinder the binding of eIF4E to HIF1 $\alpha$ 5' cap structure. Alternatively, since RBM38 physically interacts with eIF4E [9]. We hypothesize that upon binding to HIF1 $\alpha$ transcript, RBM38 and eIF4E get close together and interact with each other on the HIF $1 \alpha$ transcript, which then prevents eIF4E from associating with HIF $1 \alpha 5^{\prime}$-cap.

HIF $1 \alpha$ accumulation in tumors can be induced by various stress signals, including hypoxia in tumor microenvironment, loss of a tumor suppressor, or oncogene activation $[14,19]$. Increased HIF $1 \alpha$ abundance promotes tumor growth and angiogenesis [1, 20]. In this study, we showed that RBM38 deficiency leads to increased expression of HIF1 $\alpha$. Thus, an obvious question

\section{$\mathrm{B}$}

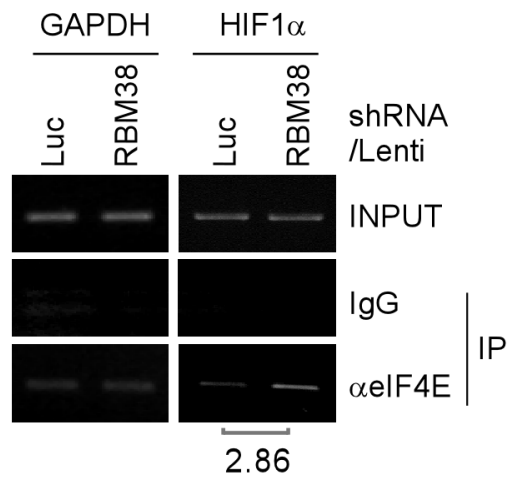

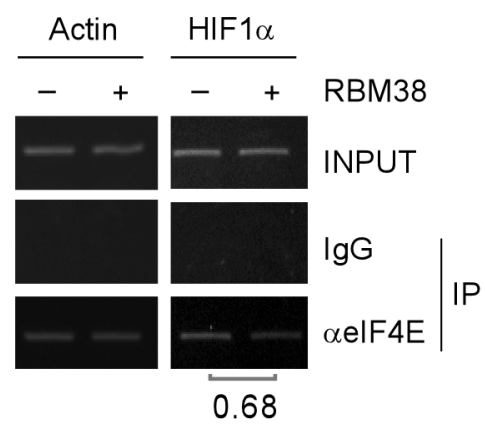

Figure 7: RBM38 prevents eIF4E from binding HIF1a transcript. (A) p53--HCT116 cells were transduced with lentivirus particles expressing a control luciferase (Luc) shRNA or RBM38 shRNA for 3 days and then cultured at a low oxygen condition, followed by immunoprecipitation with a control IgG or anti-eIF4E. Total RNAs were purified from immunocomplexes and subjected to RT-PCR analysis to measure the level of HIF $1 \alpha$ and GAPDH mRNAs. The relative level of HIF1 $\alpha$ mRNA was measured by densitometry, and the relative fold change was shown below each pair. (B) p53--HCT116 cells were uninduced (-) or induced (+) to express HA-tagged RBM38 for $48 \mathrm{~h}$ and then treated with $500 \mu \mathrm{M} \mathrm{CoCl}_{2}$ for 2 hours, followed by immunoprecipitation with a control IgG or anti-eIF4E. Total RNAs were purified from immunocomplexes and subjected to RT-PCR analysis to measure the level of HIF1 $\alpha$ and actin mRNAs. The relative level of HIF $1 \alpha$ mRNA was measured by densitometry, and the relative fold change was shown below each pair. 
would be: is there a functional connection between RBM38 and HIF1 $\alpha$ ? RBM38 is found to be overexpressed in several types of cancers [9, 21-29]. In addition, loss of RBM38 in mouse embryonic fibroblasts leads to premature senescence through activation of p53 [9]. Here, we showed that RBM38 deficiency leads to increased accumulation of HIF $1 \alpha$ under a hypoxic condition. These results suggest that both RBM38 overexpression and deficiency lead to tumor promotion. Thus, further studies are needed to address the functional link between RBM38 and HIF $1 \alpha$ under the hypoxic tumor microenvironment, which may explain how tumors thrive under a hypoxic condition. Additionally, since RBM38 expression and phosphorylation may be altered under a hypoxic condition, future studies are needed to address whether the binding of RBM38 to HIF1 $\alpha$ UTRs is affected by hypoxia.

\section{EXPERIMENTAL PROCEDURES}

\section{Plasmids}

pGEX vector expressing GST or GST-tagged RBM38 was used for producing recombinant RBM38 protein as previously described [18]. Lentiviral vectors (pLKO.1-puro) expressing shRNA against RBM38 and luciferase were prepared as previously described [8].

To generate EGFP expression vector carrying HIF1 $\alpha$ 5' and/or 3'UTRs, a DNA fragment containing EGFP coding region was amplified using pEGFP-N2 vector as a template with forward primer including HA-tag, EGFPBamHI-HA-F, and reverse primer, EGFP-R. The primers for cloning are listed in Table 1. The PCR product was digested with BamHI and NotI and cloned into pcDNA3 vector (Invitrogen). The vector was designated as pcDNA3-HA-EGFP. A fragment containing HIF $1 \alpha 5^{\prime}$ or 3'UTR was amplified using cDNA from H1299 cells as template with forward primer, HIF $1 \alpha-5^{\prime}$ UTR-KpnI-F or HIF $1 \alpha-3^{\prime}$ UTR-NotI-F, and reverse primer, HIF $1 \alpha-5^{\prime}$ UTRBamHI-R or HIF $1 \alpha-3$ 'UTR-XhoI-R. The PCR products were digested with KpnI and BamHI for HIF1 $\alpha-5$ UTR or NotI and XhoI for HIF1 $\alpha-3$ 'UTR and cloned into pcDNA3/HA-EGFP vector. The vectors were designated as pcDNA3/HIF1 $\alpha-5^{\prime} \mathrm{UTR} / \mathrm{HA}-\mathrm{EGFP}$ and pcDNA3/ HA-EGFP/HIF1 $\alpha-3$ 'UTR. To generate pcDNA3/HIF $1 \alpha-$ 5'UTR/HA-EGFP/HIF1 $\alpha-3$ 'UTR, pcDNA3/HIF1 $\alpha-5$ 'UTR/ HA-EGFP vector was digested with $K p n \mathrm{I}$ and BamHI. The digested DNA fragment containing HIF $1 \alpha-5^{\prime} \mathrm{UTR}$ was cloned into pcDNA3/HA-EGFP/HIF $1 \alpha-3$ 'UTR. The HIF $1 \alpha-3$ 'UTR deletion mutation was generated from two cDNA fragments using two-steps PCRs with HIF1 $\alpha$ 3'UTR-NotI-F and HIF1 $\alpha-3$ 'UTR-XhoI-R, followed by subcloning into pcDNA3-HA-EGFP. The fragment 1 was amplified using primers HIF $1 \alpha-3$ 'UTR-NotI-F and HIF $1 \alpha-$ 3'UTR-mut-R whereas the fragment 2 was produced using primers HIF $1 \alpha-3^{\prime}$ UTR-mut-F and HIF $1 \alpha-3^{\prime}$ UTR-XhoI-R.

\section{Cell culture}

Human breast cancer MCF7 cell line, Human colorectal carninoma HCT116 cell line, and human non-small cell lung carcinoma H1299 cell line were obtained from the American Type Culture Collection (ATCC, Manassas, VA). p53 ${ }^{-/-}$HCT116 cell line was used as described [30]. Cell lines were cultured in DMEM (Invitrogen) supplemented with 10\% fetal bovine serum (Hyclone) and maintained at $37^{\circ} \mathrm{C}$ in a humidified $5 \%$ $\mathrm{CO}_{2}$. p53-null HCT116 cell lines, in which RBM38 can be inducibly knocked down or in which RBM38, RBM38-S195A, or RBM38-S195D can be inducibly expressed, were generated and cultured as previously described $[7,10,17]$. Cells were subjected to hypoxia $(0.1$ to $1 \%$ ) by exposure to $10 \% \mathrm{H}_{2} / 5 \% \mathrm{CO}_{2}$ /balanced $\mathrm{N}_{2}$ at $37^{\circ} \mathrm{C}$ in Forma 1025/1029 Anaerobic Chamber (Thermo Scientific).

\section{RNA interference}

For lentiviral shRNA transduction, a lentiviral vector $(10 \mu \mathrm{g})$ expressing shRNA against luciferase or RBM38 [17], along with packaging plasmids, pRSVREV $(5 \mu \mathrm{g}), \mathrm{pMDL} \mathrm{g} / \mathrm{p}$ RRE $(5 \mu \mathrm{g})$, and VSVG $(5 \mu \mathrm{g})$, was cotransfected into HEK $293 \mathrm{~T}$ cells $\left(8 \times 10^{6}\right)$ with Expressfect transfection reagent (Denville Scientific). After $48 \mathrm{~h}$, the supernatant containing shRNAexpressing lentiviral particles was harvested, filtered and concentrated by ultracentrifugation $\left(25,000 \mathrm{rpm}, 4^{\circ} \mathrm{C}, 2\right.$ h). The concentrated lentiviral particles were then used to transduce cells, followed by puromycin selection $(1 \mu \mathrm{g}$ $/ \mathrm{ml}$ ) for 3 days to remove un-transduced cells. RBM38 siRNA was used as described $[9,17]$.

\section{Western blot analysis}

Cells were cultured in various conditions and whole cell lysates were prepared with $2 \mathrm{X}$ SDS sample buffer. Whole cell lysates were separated in 8 to $12 \%$ SDS-PAGE, transferred to a nitrocellulose membrane, and incubated with primary and secondary antibodies, followed by enhanced chemiluminescent detection. The antibodies used in this study are anti-HIF $1 \alpha$ (BD Biosciences), antiRBM38 (purified rabbit polyclonal), anti-p53 (monoclonal anti-serum, DO-1), and anti-Actin (Sigma).

\section{RNA isolation, RT-PCR}

Total RNA was isolated by using Trizol reagent (Invitrogen). cDNA was synthesized using MMLV reverse transcriptase (Promega). PCR was performed with primers 
Table 1: Primers for RT-PCR and cloning

\begin{tabular}{|c|c|}
\hline Primer Name & Sequence \\
\hline RBM38-RT-F & 5'-cgcagaaggacaccacgttcacca-3' \\
\hline RBM38-RT-R & $5^{\prime}$-tgtagtgcggggtcagcccgtct-3' \\
\hline HIF $1 \alpha-R T-F$ & 5'-cacaggaaatggccttgtgaa-3' \\
\hline HIF1 $\alpha-R T-R$ & 5'-ccaagcaggtcataggtggt- $3^{\prime}$ \\
\hline GAPDH-RT-F & $5^{\prime}$-agcctcaagatcatcagcaatg-3' \\
\hline GAPDH-RT-R & 5'-atggactgtggtcatgagtcctt-3' \\
\hline HIF $1 \alpha-5 U T-K p n-F$ & 5'-gggGGTACCgcgcgcgccggcctgggcag-3' \\
\hline HIF $1 \alpha-5 U T-B a m-R$ & 5'-gggGGATCCGGTGAATCGGTCCCCGCGAT-3' \\
\hline HIF1 $\alpha-3 U T-N o t-F$ & $\begin{array}{l}\text { 5'-gGCGGCCGCgctttttcttaatttcattcctttttttggac } \\
\text { actg -3' }\end{array}$ \\
\hline HIF $1 \alpha-3$ UT-Xho-R & 5'-gggCTCGAGGCCTGGTCCACAGAAGATG-3' \\
\hline HIF $1 \alpha-3$ UT mut-F & $\begin{array}{l}\text { CAGTAGCATCGTTTATCCCTTTTTCGAATTATTTT } \\
\text { TAAGAAGATGCCAATATAATTTTTGTAAGAAGGC }\end{array}$ \\
\hline HIF $1 \alpha-3$ UT mut-R & $\begin{array}{l}\text { GGGATAAACGATGCTACTGCAATGCAATGGTTTAA } \\
\text { ATACCAAAAAACTGAGAAAATGAG }\end{array}$ \\
\hline EGFP-HA-Bam-F & $\begin{array}{l}\text { 5'-ggggGGATCCgccaccatgTACCCATACGATGTT } \\
\text { CCAGATTACGCTgtgagcaagggcgaggagctg-3' }\end{array}$ \\
\hline EGFP-R & 5'-GTATGGCTGATTATGATCTAG-3' \\
\hline
\end{tabular}

listed in Table 1.

\section{RNA-immunoprecipitation (RNA-IP)}

RNA-IP was carried out as previously described $[7,31]$. Briefly, cells $\left(4 \times 10^{6}\right)$ were lysed with $1 \mathrm{ml}$ of lysis buffer (10 mM HEPES, pH7.0, $100 \mathrm{mM} \mathrm{KCl,} 10$ $\mathrm{mM} \mathrm{MgCl}_{2}, 0.5 \%$ NP-40, 1 mM DTT) supplemented with RiboLock Ribonuclease inhibitor (Fermentas) for 15 min on ice. Cell lysates were collected following centrifugation $\left(13,000 \mathrm{rpm}, 4^{\circ} \mathrm{C}, 10 \mathrm{~min}\right)$. The RNAprotein immunocomplexes were formed by incubating $0.4 \mathrm{ml}$ of cell lysates with $2 \mu \mathrm{g}$ of anti-RBM38 (purified rabbit polyclonal), anti-eIF4E (Santa Cruz, CA), or isotype control IgG at $4{ }^{\circ} \mathrm{C}$ for $4 \mathrm{~h}$ and brought down by $20 \mu \mathrm{l}$ of protein $\mathrm{G}$ bead (50\% slurry). RT-PCR analysis was carried out to measure the RNA-protein interaction. The primers to amplify p21 were used as described in [9].

\section{Probe preparation and RNA Electrophoretic Mobility Shift Assay (REMSA)}

All probes were labeled by in vitro transcription using a DNA fragment containing T7 promoter and various region of HIF1 $\alpha 5^{\prime}$ or 3'UTR. Briefly, $500 \mathrm{ng}$ of purified PCR product was incubated with $50 \mu \mathrm{Ci}$ of $\alpha-{ }^{32}$ P-UTP, $0.5 \mathrm{mM}$ each of NTP (A, G, C), 20 unit of T7 RNA polymerase (Ambion) in $20 \mu \mathrm{l}$ of reaction at $37^{\circ} \mathrm{C}$ for $1 \mathrm{~h}$, followed by DNase I (1 unit) treatment for $15 \mathrm{~min}$. The reaction mixture was purified by Sephadex G-50 column to remove unlabeled free nucleotides and the radioactivity of probes was measured by a scintillation counter. REMSA was carried out with a modified protocol as previously described [8]. Briefly, $250 \mathrm{nM}$ of RBM38 recombinant protein, $100 \mu \mathrm{g} / \mathrm{ml}$ of yeast tRNA, and $50,000 \mathrm{CPM}{ }^{32} \mathrm{P}$-labeled RNA probe were mixed in 20 $\mu \mathrm{l}$ of reaction buffer (10 mM Tris- $\mathrm{Cl}, \mathrm{pH} 8.0,25 \mathrm{mM}$ $\mathrm{KCl}, 10 \mathrm{mM} \mathrm{MgCl}, 1 \mathrm{mM} \mathrm{DTT}$ ) at $25^{\circ} \mathrm{C}$ for $25 \mathrm{~min}$. RNA/protein complexes were digested with $100 \mathrm{U}$ RNase $\mathrm{T} 1$ at $37^{\circ} \mathrm{C}$ for $15 \mathrm{~min}$ and then separated in $7 \%$ native PAGE gel. RNA-protein complexes were visualized by autoradiography.

\section{${ }^{35}$ S-Metabolic labeling Assay}

Cells seeded in a $6-\mathrm{cm}$ plate $\left(6 \times 10^{6}\right.$ cells $)$ were washed twice with PBS and incubated in DMEM without L-methionine and L-cysteine for $1 \mathrm{~h}$. Cells were then labeled with $100 \mu \mathrm{Ci} / \mathrm{ml}$ Easy Tag EXPRESS ${ }^{35} \mathrm{~S}$ Protein Labeling Mix (PerkinElmer) for $30 \mathrm{~min}$. Cell lysates were isolated and used for immunoprecipitation with antiHIF $1 \alpha$ (H1 $\alpha 67$, Sigma) or non-immune mouse IgG. The samples from immunoprecipitation were separated in $8 \%$ SDS/PAGE. The gel was dried on 3-MM paper and the protein signals were captured by autoradiography. 


\section{ACKNOWLEDGMENTS}

This work is supported in part by NIH grants (CA076069, CA081237 and CA121137).

\section{Authors' contribution}

Cho SJ, Teng IF, Zhang M, Yin T, and Jung YS did the experiments. Cho SJ, Teng IF, Zhang M, Yin T, Jung YS and Zhang $\mathrm{J}$ analyzed the data; Chen $\mathrm{X}$ supervised the project and analyzed the data; Cho SJ, Teng IF, and Chen $\mathrm{X}$ wrote the manuscript. All authors read and commented on the draft version of the manuscript and approved the final version.

\section{REFERENCES}

1. Harris AL. Hypoxia--a key regulatory factor in tumour growth. Nature reviews Cancer. 2002;2(1):38-47.

2. Brown JM, Wilson WR. Exploiting tumour hypoxia in cancer treatment. Nature reviews Cancer. 2004;4(6):437-47.

3. Schofield CJ, Ratcliffe PJ. Oxygen sensing by HIF hydroxylases. Nature reviews Molecular cell biology. 2004;5(5):343-54.

4. Huang LE. Biochemistry. How HIF-1alpha handles stress. Science. 2013;339(6125):1285-6.

5. Koshiji M, Kageyama Y, Pete EA, Horikawa I, Barrett JC, Huang LE. HIF-1alpha induces cell cycle arrest by functionally counteracting Myc. The EMBO journal. 2004;23(9):1949-56.

6. Hubbi ME, Kshitiz, Gilkes DM, Rey S, Wong CC, Luo W, Kim DH, Dang CV, Levchenko A, Semenza GL. A nontranscriptional role for HIF-1alpha as a direct inhibitor of DNA replication. Science signaling. 2013;6(262):ra10.

7. Shu L, Yan W, Chen X. RNPC1, an RNA-binding protein and a target of the p53 family, is required for maintaining the stability of the basal and stress-induced p21 transcript. Genes Dev. 2006;20(21):2961-72.

8. Cho SJ, Jung YS, Zhang J, Chen X. The RNA-binding protein RNPC1 stabilizes the mRNA encoding the RNAbinding protein $\mathrm{HuR}$ and cooperates with HuR to suppress cell proliferation. J Biol Chem. 2012;287(18):14535-44.

9. Zhang J, Cho SJ, Shu L, Yan W, Guerrero T, Kent M, Skorupski K, Chen H, Chen X. Translational repression of p53 by RNPC1, a p53 target overexpressed in lymphomas. Genes Dev. 2011;25(14):1528-43.

10. Zhang J, Jun Cho S, Chen X. RNPC1, an RNA-binding protein and a target of the p53 family, regulates p63 expression through mRNA stability. Proc Natl Acad Sci U S A. 2010;107(21):9614-9.

11. $\mathrm{Xu} \mathrm{E}$, Zhang J, Chen X. MDM2 expression is repressed by the RNA-binding protein RNPC1 via mRNA stability. Oncogene. 2013;32(17):2169-78.
12. Yan W, Zhang J, Zhang Y, Jung YS, Chen X. p73 expression is regulated by RNPC1, a target of the p53 family, via mRNA stability. Molecular and cellular biology. 2012;32(13):2336-48.

13. Yin T, Cho SJ, Chen X. RNPC1, an RNA binding protein and a p53 target, regulates MIC-1 expression through mRNA stability. The Journal of biological chemistry. 2013.

14. Ravi R, Mookerjee B, Bhujwalla ZM, Sutter CH, Artemov D, Zeng Q, Dillehay LE, Madan A, Semenza GL, Bedi A. Regulation of tumor angiogenesis by p53-induced degradation of hypoxia-inducible factor 1alpha. Genes \& development. 2000;14(1):34-44.

15. Semenza GL. HIF-1: upstream and downstream of cancer metabolism. Curr Opin Genet Dev. 2010;20(1):51-6.

16. Galban S, Kuwano Y, Pullmann R, Jr., Martindale JL, Kim HH, Lal A, Abdelmohsen K, Yang X, Dang Y, Liu JO, Lewis SM, Holcik M, Gorospe M. RNA-binding proteins $\mathrm{HuR}$ and PTB promote the translation of hypoxia-inducible factor 1alpha. Mol Cell Biol. 2008;28(1):93-107.

17. Zhang M, Zhang J, Chen X, Cho SJ, Chen X. Glycogen synthase kinase 3 promotes p53 mRNA translation via phosphorylation of RNPC1. Genes Dev. 2013;27(20):224658.

18. Cho SJ, Zhang J, Chen X. RNPC1 modulates the RNA-binding activity of, and cooperates with, HuR to regulate p21 mRNA stability. Nucleic acids research. 2010;38(7):2256-67.

19. Lim JH, Lee ES, You HJ, Lee JW, Park JW, Chun YS. Rasdependent induction of HIF-1alpha785 via the Raf/MEK/ ERK pathway: a novel mechanism of Ras-mediated tumor promotion. Oncogene. 2004;23(58):9427-31.

20. Zhong H, De Marzo AM, Laughner E, Lim M, Hilton DA, Zagzag D, Buechler P, Isaacs WB, Semenza GL, Simons JW. Overexpression of hypoxia-inducible factor 1alpha in common human cancers and their metastases. Cancer research. 1999;59(22):5830-5.

21. Bar-Shira A, Pinthus JH, Rozovsky U, Goldstein M, Sellers WR, Yaron Y, Eshhar Z, Orr-Urtreger A. Multiple genes in human 20q13 chromosomal region are involved in an advanced prostate cancer xenograft. Cancer Res. 2002;62(23):6803-7.

22. Carvalho B, Postma C, Mongera S, Hopmans E, Diskin S, van de Wiel MA, van Criekinge W, Thas O, Matthäi A, Cuesta MA, Terhaar Sive Droste JS, Craanen M, Schröck E, Ylstra B, Meijer GA. Multiple putative oncogenes at the chromosome $20 \mathrm{q}$ amplicon contribute to colorectal adenoma to carcinoma progression. Gut. 2009;58(1):79-89.

23. Ginestier C, Cervera N, Finetti P, Esteyries S, Esterni B, Adelaide J, Xerri L, Viens P, Jacquemier J, Charafe-Jauffret E, Chaffanet M, Birnbaum D, Bertucci F. Prognosis and gene expression profiling of 20q13-amplified breast cancers. Clinical cancer research : an official journal of the American Association for Cancer Research. 2006;12(15):4533-44.

24. Hermsen M, Postma C, Baak J, Weiss M, Rapallo A, 
Sciutto A, Roemen G, Arends JW, Williams R, Giaretti W, De Goeij A, Meijer G. Colorectal adenoma to carcinoma progression follows multiple pathways of chromosomal instability. Gastroenterology. 2002;123(4):1109-19.

25. Knosel T, Schluns K, Stein U, Schwabe H, Schlag PM, Dietel M, Petersen I. Genetic imbalances with impact on survival in colorectal cancer patients. Histopathology. 2003;43(4):323-31.

26. Korn WM, Yasutake T, Kuo WL, Warren RS, Collins C, Tomita M, Gray J, Waldman FM. Chromosome arm 20q gains and other genomic alterations in colorectal cancer metastatic to liver, as analyzed by comparative genomic hybridization and fluorescence in situ hybridization. Genes Chromosomes Cancer. 1999;25(2):82-90.

27. Krackhardt AM, Witzens M, Harig S, Hodi FS, Zauls AJ, Chessia M, Barrett P, Gribben JG. Identification of tumorassociated antigens in chronic lymphocytic leukemia by SEREX. Blood. 2002;100(6):2123-31.

28. Letessier A, Sircoulomb F, Ginestier C, Cervera N, Monville F, Gelsi-Boyer V, Esterni B, Geneix J, Finetti P, Zemmour C, Viens P, Charafe-Jauffret E, Jacquemier J, Birnbaum D, Chaffanet M. Frequency, prognostic impact, and subtype association of 8p12, 8q24, 11q13, 12p13, $17 \mathrm{q} 12$, and $20 \mathrm{q} 13$ amplifications in breast cancers. BMC Cancer. 2006;6:245.

29. Tanner MM, Grenman S, Koul A, Johannsson O, Meltzer P, Pejovic T, Borg A, Isola JJ. Frequent amplification of chromosomal region 20q12-q13 in ovarian cancer. Clin Cancer Res. 2000;6(5):1833-9.

30. Bunz F, Dutriaux A, Lengauer C, Waldman T, Zhou S, Brown JP, Sedivy JM, Kinzler KW, Vogelstein B. Requirement for p53 and p21 to sustain G2 arrest after DNA damage. Science. 1998;282(5393):1497-501.

31. Peritz T, Zeng F, Kannanayakal TJ, Kilk K, Eiriksdottir E, Langel U, Eberwine J. Immunoprecipitation of mRNAprotein complexes. Nat Protoc. 2006;1(2):577-80. 